\title{
Simple models of two-dimensional information sources and codes
}

Justesen, Jørn; Shtarkov, Y. M.

Published in:

Information Theory, 1998. Proceedings. 1998 IEEE International Symposium on

Link to article, DOI:

10.1109/ISIT.1998.709017

Publication date:

1998

Document Version

Publisher's PDF, also known as Version of record

Link back to DTU Orbit

Citation (APA):

Justesen, J., \& Shtarkov, Y. M. (1998). Simple models of two-dimensional information sources and codes. In Information Theory, 1998. Proceedings. 1998 IEEE International Symposium on IEEE.

https://doi.org/10.1109/ISIT.1998.709017

\section{General rights}

Copyright and moral rights for the publications made accessible in the public portal are retained by the authors and/or other copyright owners and it is a condition of accessing publications that users recognise and abide by the legal requirements associated with these rights.

- Users may download and print one copy of any publication from the public portal for the purpose of private study or research.

- You may not further distribute the material or use it for any profit-making activity or commercial gain

- You may freely distribute the URL identifying the publication in the public portal

If you believe that this document breaches copyright please contact us providing details, and we will remove access to the work immediately and investigate your claim 


\section{Simple Models of Two-Dimensional Information Sources and Codes}

\author{
Jørn Justesen \\ Department of Telecommunication \\ Building 371 Technical University of Denmark, DK-2800 \\ Lyngby, Denmark \\ E-mail: jju@tele.dtu.dk
}

Abstract - We consider discrete random fields which have simple descriptions of rows and columns. We present constructions which combine high entropy with simple means of generating the fields and analyzing the probability distribution. Hidden state Markov sources are an essential tool in the construction.

\section{INTRODUCTION}

We shall consider two-dimensional fields on a rectangular grid. The variables, $u_{i j}$, take values from a finite set. The fields might be defined by a set of local constraints reflecting properties of the codes or images under consideration, and it would be desirable to have models with a large entropy [1].

\section{FIELDS FROM FIRST ORDER MARKOV CHAINS}

We shall consider the particular case of fields with rows and columns described by the same first order Markov chain, and in addition we require that each row depends on the upper half plane only through the last row.

Let $m$ be the size of the alphabet, $W=\left\{w_{1}, w_{2}, \ldots w_{m}\right\}$, and equivalently, the number of states in the chain. We shall assume that the chain is regular with transition matrix $Q$. In order to obtain a simple link between two rows and what is often referred to as a causal model for generating the field, it is desirable that $u_{i j}$ depends on the previous row and symbols in the same row to the left only though $u_{i j-1}, u_{i-1 j}$, and $u_{i-1 j-1}$.

Markov chains with pairs of symbols as the alphabet will be used to describe the simultaneous distribution of two rows. Let $\mathrm{P}\left(\mathrm{x}^{\mathrm{n}}, \mathrm{y}^{\mathrm{n}}\right)$ indicate the simultaneous distribution of two rows, and use the chain rule to express this probability as a product of conditional probabilities

$$
P\left(x^{n}, y^{n}\right)=\prod Q\left(x_{i}, y_{i} \mid x^{i-1}, y^{i-1}\right)
$$

Lemma $1:$. If the conditional probability of $\mathrm{x}_{\mathrm{i}}$ depends only on $x_{i-1}$, then $x^{n}$ is a Markov chain.

If we make a similar independence assumption about $y$ ", we can assure that this row becomes a Markov chain, but the only solution is the Pickard field [2]. We shall maintain the independence assumption for the first row. However, the marginal distribution of the second row will be described by a partially hidden-state process, where the state is defined by the present

\author{
Yuri M. Shtarkov \\ Institute for Problems of Information Transmission \\ Russian Academy of Sciences \\ 101447, Moscow, GSP-4, B. Karetnyi per.19, Russia \\ E-mail: shtarkov@ippi.ras.ru
}

symbol and the probability distribution on the symbol in the previous row. In order for the hidden state process to reduce to a usual Markov chain, the hidden state must be a function of the observable part.

Lemma 2: A necessary condition for the lower row to be a Markov chain with transition matrix $Q$ is that $Q G=G Q$ where $\mathrm{G}$ is the linear mapping defining the hidden state.

Theorem 1: There is a probability assignment such that all rows are generated left to right and all columns from the bottom to the top by the transition matrix $Q$.

Example 1: The constraint known as the hard square model (and several other names) is that $u_{i j}=1$ only if $u_{i-1 j}=0$ and $u_{i j-1}$ $=0$. For $P(1)=1 / 5, P\left(u_{i j}=1 \mid u_{i-1 j}=0, u_{i j-1}=0\right)=4 / 13$. The entropy becomes $(13 / 20) \cdot \mathrm{H}(4 / 13)=0.5788$.

Example 2: Consider binary fields which have rows and columns described by symmetric binary Markov chains. We shall take the transition probability between the two colors to be $1 / 5$. Taking $\mathrm{P}(01 / 10)=0$, the boundaries between the two colours become closed, non-intersecting curves. In [3] we used this field as an intermediate step in the construction of a balanced ternary field. The entropy is easily calculated as $\mathrm{H}=0.4756$ for the Pickard field, but $\mathrm{H}=0.5359$ for the field constructed using a hidden state model. Comparing samples of the two fields, the latter sample has a more random appearance, but the difference in the correlations along the diagonals is quite obvious.

\section{FIELDS FROM SECOND ORDER MARKOV CHAINS.}

We shall extend our approach to the case where rows and columns are described by a second order Markov chain, and each row depends on the upper half plane only through the last two rows.

\section{REFERENCES:}

[1] S. Forchhammer \& J. Justesen, "Entropy bounds for constrained two-dimensional random fields", to appear in IEEE Trans. Info. Th.

[2]. D.K. Pickard, "A curious binary lattice process", J. Appl. Prob., Vol. 14, pp 717-731, 1977.

[3] J. Justesen, "Bounds on Constrained Codes in One and Two Dimensions", to appear in Codes, Curves, and Signals: Common Threads in Communications, presented in Urbana, Illinois September, 1997. 